\title{
The emergency department nursing workforce: Local solutions for local issues
}

Christine M. Duffield RN, PhD, MHP, BScN (Professor and Director) ${ }^{a}$, Lisa Conlon RN, BSc, MClincNurs, DNurs(c) (Lecturer, 3rd Year Undergraduate Coordinator) ${ }^{\mathrm{b}}$, Michelle Kelly MN, BSc, RN, PhD (c) (Lecturer, Project Manager) ${ }^{\mathrm{c}}$, Christine Catling-Paull MSc, RM, RN (Research Assistant) ${ }^{\mathrm{a}}$, Helen Stasa BA (Hons) BA (Hons) (Research Assistant) ${ }^{\mathrm{a}}$

${ }^{a}$ Centre for Health Services Management, Faculty of Nursing, Midwifery and Health, University of Technology, Sydney, Australia

' Faculty of Nursing, Midwifery and Health, University of Technology, Sydney, Australia

Curriculum Technologies Integration, Faculty of Nursing, Midwifery and Health, University of Technology, Sydney, Australia

\section{Introduction}

As in many countries, emergency departments (EDs) in Australia have become much busier, providing care to more complex patients in greater numbers than ever before. In 2007-2008, there were over seven million presentations to EDs in Australian public hospitals (Australian Institute of Health and Welfare, 2009). The first contact many patients have with a hospital is via the ED, which unlike a hospital's reception area, can be a highly charged environment, perceived as 'chaotic' and frightening for patients and their families. The targets by which ED performance is measured in Australia (for example waiting times) places an even greater burden on hospitals and staff, as failure to meet targets is often sensationalised by the media. This paper will examine some of the challenges which impact on the ED nursing workforce and evaluate approaches which may be introduced to deal with these.

\section{Emergency departments today}

The ED is a place of high activity where staff are expected to care for a wide range of unanticipated presentations. They deal with life and death situations; presentations which are better suited to treatment by a General Practitioner (GP) such as minor respiratory infections and lacerations; provide care for the full age spectrum from newborns to the elderly; and a growing number of presentations which are 'psychosocial' in nature - including homelessness and issues related to child protection (Gardner et al., 2000). In addition, the ED must accept, treat and manage all cases as they present, as failure to do so in a timely manner often results in intense media scrutiny (Lauder, 2007).

One of the most significant pressures facing Australian EDs is the increase in patient attendances. With shortages of beds in the acute hospital system, often the fastest route to hospital admission is via the ED. In 2007-2008 there were seven million occasions of service (attendances), rising an average of 4.9\% each year since 2002-2003 (Australian Institute of Health and Welfare, 2009). A similar increase in attendances is expected in future years. A recent cluster analysis report of two major Sydney hospital EDs (New South Wales Health, 
2007) highlighted a number of key issues which have substantially increased demand for services including an ageing population; more patients presenting with multiple comorbidities; an increased number of patients with chronic disease(s); the increased cultural diversity of patients; and increased acuity on presentation. In addition, with the number of GPs declining and pressure from this group to increase the fee paid by patients for their services, it is likely that more patients with minor ailments will present to an ED (known as 'walk-ins') in an effort to obtain fast, free care. This will add further to increased demand. (Australian Institute of Health and Welfare, 2008, 2009; Australian Medical Association, 2005; Elliot, 2002; Metherell, 2003). At the other end of the care continuum, there are now often increased levels of intervention undertaken in the ED rather than in the intensive care unit (ICU) or ward/unit areas, also increasing patients' waiting time (Wilper et al., 2008).

State and Territory Governments in Australia are responsible for managing hospitals efficiently and effectively, using targets designed to improve access, decrease waiting times and decrease delays in treatment. Current target measures include average ED waiting times (the time to be seen by an emergency physician); average time to transfer to ward; and time off stretcher (the amount of time taken from ambulance arrival to transfer of care to hospital ED) (Australian Institute of Health and Welfare, 2008) and these figures are publicised. For example, recent data indicate that median ED waiting time in Australian public hospitals was 24 minutes with $69 \%$ of patients being seen within their triage category recommended time (Australian Government Department of Health and Ageing, 2009). However, at times the targets can result in adverse consequences. For instance, the policy of 'treat and release quickly' may result in patients being discharged home only to return more seriously ill the next day or shortly after this initial discharge (Brown and Gray, 1998; Demir et al., 2008). Actions taken to decrease crowding by increasing throughput in the ED may cause congestion in other departments and hospital wards (Committee on the Future of Emergency Care in the United States Health System, 2006; Harrison et al., 2007; Robert Wood Johnson Foundation, 2009). In addition, rapid throughputs may compromise the continuity of patient care, requiring implementation of strategies to improve information sharing and handover to prevent adverse events (FitzPatrick et al., 2006; Maloney et al., 2007; Shendell-Falik et al., 2007; Vincent and Wears, 2002). 
There are also hospital-wide factors which may increase 'congestion' in the ED. The most significant of these is the shortage of beds (Mark, 2009; Sammut, 2009). Over the past 25 years, the number of acute public hospital beds in Australia has been reduced from 74,000 beds to approximately 56,000 beds (Sammut, 2009). In 2007, more than a third of patients requiring hospital admission after ED treatment waited in excess of eight hours for a bed to become available (Wallace, 2007). Anything which prevents the transfer of patients immediately to an available bed significantly impacts on the efficiency of the ED. When bed capacity is limited, patients may be admitted to any available bed (known as 'hotbedding' in Australia). This then results in nurses moving inpatients around to accommodate new admissions because there is no bed available in the appropriate unit or ward type. In a recent study Duffield et al. (2009a) found that 1.25 patients flowed through each medical or surgical bed every day, and that the average number of wards/units patients visited per admission was increasing. This figure did not include transfers between beds on the same ward. As a consequence of delayed transfer, ED staff are often exposed to 'abuse from exasperated and irate patients, their family members or friends, when their expectations for prompt quality care are unable to be met' (College of Emergency Nursing Australasia, 2007, p. 1).

There are other workforce factors affecting the efficiency of the ED. These include a reduction in junior doctors' working hours, nursing shortages, a shortage of senior medical staff and multiple health professionals working in the same department with overlapping competencies (Garling, 2008), where lines of communication and authority are not always clear and role responsibilities 'blur'. As it is unlikely that this situation will resolve quickly it is timely to evaluate strategies which may be employed to 're-design' the workforce.

\section{Workforce strategies to improve performance}

As the highly charged 'face' of the health care system any failure to meet demand or targets in the ED are often seized upon by the media. Faced with situations such as this, rapid responses are required from health service managers and these often take the form of redesigning or changing workforce roles and responsibilities to improve departmental performance. The authors will use two hypothetical hospital EDs (designated Hospital A and Hospital B) to illustrate four approaches to workforce re-design (see Table 1). 
Table 1 - An overview of two hypothetical hospital EDs

\begin{tabular}{ll}
\hline \multicolumn{1}{c}{ Hospital A } & Hospital B \\
\hline Satellite teaching hospital of 200 beds & Satellite teaching hospital of 200 beds \\
Average $102 \%$ occupancy & Average $99 \%$ occupancy \\
22,300 ED attendances & 19,590 ED attendances \\
$33 \%$ ED attendances admitted & $45 \%$ ED attendances admitted \\
ED nurse staffing numbers similar & ED nurse staffing numbers similar \\
$90 \%$ RN mix & $100 \%$ RN mix \\
Staff specialist all times & Staff specialist all times \\
Nurse practitioner & Allied health support \\
Holding ward & \\
Community liaison team & \\
Paediatric service & \\
Targets & \\
Triage 1 target met (100\%) & \\
Triage $2-81 \%$ & Triage 1 target met $(100 \%)$ \\
Triage $3-75 \%$ in 30 min & Triage $2-68 \%$ \\
Triage $4-70 \%$ in 1 hour & Triage $3-60 \%$ in 30 min \\
$20 \%$ left untreated & Triage $4-45 \%$ in 1 hour \\
Average waiting time 35 min & $45 \%$ left untreated \\
Access (ward) in 8 hours $-80 \%$ & Average waiting time 65 min \\
Access (ward) in 6 hours $-80 \%$ & Access (ward) in 8 hours $-75 \%$ \\
Average time to ward -7.49 hours & Access (ward) in 6 hours $-75 \%$ \\
Discharge $<4$ hours - $80 \%$ & Average time to ward -11.62 hours \\
Off-stretcher $<30$ min. - $90 \%$ & Off-stretcher $<30$ min. - $60 \%$ \\
\hline
\end{tabular}

From the perspective of a hospital manager there are several inferences which can be drawn from these data. First, whilst there are some differences in service types and staffing between the two hospitals, Hospital A meets more targets at a higher rate, admits fewer patients, has a faster throughput, uses fewer registered nurse (RN) resources, has a nurse practitioner (NP) on staff and the costs/patient are less. In the absence of any other data a health service manager might conclude that introducing a new role to Hospital B - that of a NP - will result in similar (and better) outcomes. Various researchers have found evidence to support the suggestion that NPs can have a positive impact on patient care and satisfaction (Guzik et al., 2009; Jennings et al., 2009; Sackett, 2009). For instance, in a longitudinal study of patients in Canada, Sackett (2009) reported no differences in the health status of patients who received 
standard clinical care from a physician compared to those who received care from a NP. In the occupational health setting, Guzik et al. (2009) found no difference in satisfaction between patients treated by physicians compared with patients treated by NPs, whilst in their study of patient satisfaction in an Australian metropolitan ED, Jennings et al. (2009) found that patients treated by a NP reported higher levels of satisfaction than did patients treated by an ED doctor. The introduction of a NP to Hospital B might be the most simple approach and very appropriate but it should also take into account local issues such as patient demographics and staff mix, availability of a qualified NP and medical opposition or support for such a position (Elsom et al., 2009).

A second strategy, rather than introducing a NP, is to introduce another nursing role. Changes in the way that health care is managed, organised and structured have resulted in widespread changes to nursing roles. These changes have included the introduction of new roles not previously present in EDs (such as Emergency Nurse Practitioners), as well as the expansion and modification of pre-existing roles (McKenna et al., 2009). A brief review of the literature found the following position titles (Table 2) working in EDs (Currie et al., 2007; Hooker, 2004, 2006; Hudson and Marshall, 2008; Jarman, 2007; Jennings et al., 2008; Root, 2008; Wilson and Shifaza, 2008):

\section{Table 2 - ED position titles}

ED advanced practice nurse (EDAPN) (Hudson and Marshall, 2008, Root, 2008)

Emergency nurse practitioners (ENP) (Currie et al., 2007, Hudson and Marshall, 2008, Jennings et al., 2008, Wilson and Shifaza, 2008)

Consultant nurse in emergency care (CNEC)

Emergency care nurse (ECN) (Jarman, 2007)

ED resuscitation nurse (EDRN)

Nurse registrar, honorary nurse registrar

ED Physician assistant (Hooker, 2006, 2004)

There may be several problems which arise from this approach of introducing new nursing roles. From the titles in Table 2 it is unclear what the functions of the positions are, and how they might be different or similar. It is possible that while the titles are different, incumbents may undertake similar duties. Staff and patients may have little idea what the skill set or knowledge level is of those providing their care (Duffield et al., 2009b; McKenna et al., 
2009). Most worrying is that some may perform similar functions to a NP, a title which is controlled and legislated, denoting a registered nurse who has been assessed as competent according to a set of national standards and granted authorisation to function autonomously in a clinical role (Australian Nursing and Midwifery Council, 2006; NSW Department of Health, 2005).

Conversely, difficulties may arise if the same position title is used to refer to quite different roles. A simple example is the role of the Clinical Nurse Specialist (CNS), which differs between the United States (US) and Australia. In the US, this position is an advanced practice registered nurse role, with CNSs undertaking activities such as the delivery of complex patient care, consulting on complex nursing problems, and developing appropriate nursing tools to evaluate patient care, learning and quality. In contrast, in NSW (Australia) a clinical nurse specialist is a personal grade awarded to individual nurses on the basis of expertise in a specialty demonstrated by qualifications and/or experience (NSW Health, 2005). While the nomenclature is the same, the functions and roles undertaken are quite different. There can be confusion over tasks and duties given the lack of regulation and legislation which may surround the establishment of these positions (Daly and Carnwell, 2003; Rutherford et al., 2005). Inefficiencies such as work duplication (Roschkov et al., 2004) can result and there may be medico-legal-regulatory difficulties if nurses are faced with disciplinary procedures resulting from a lack of clear-cut standards of practice. These considerations suggest that when introducing 'new' roles, nursing executives need to take care to ensure that the roles and responsibilities are clear to both staff and patients (Buchan et al., 2001; Pearson, 2003).

A third strategy is to change or re-design the functions and tasks within current roles. There are a number of reasons why such a strategy may be implemented. First, if there are certain tasks or functions which are not being covered adequately, redesigning current roles may assist in reducing deficiencies by giving particular staff responsibility for the tasks or conversely, doing this may assist in eliminating overlap between related roles. Role overlap or ambiguity is a costly phenomenon. It has been found to be associated with decreased job satisfaction, as well as a reduction in the number and quality of applicants for positions (Duffield et al., 1994; McKenna et al., 2009). However, role restructuring and clarification may assist in ensuring that staff members are able to better utilise their professional skills and 
knowledge and gain more job satisfaction. For instance, in their study of nurses' reports of hospital care across five different countries, Aiken et al. (2001) found that nurses reported spending a considerable amount of time performing functions (such as transporting food trays) which did not call upon their professional skills, whilst care activities requiring their expertise were frequently left incomplete. Changing or adjusting a role may help to ensure that staff are engaged in activities which require their specialised skills.

This change of roles may also occur between the regulated health professions (medical, nursing, and allied health staff) in acknowledgement of the expertise of one discipline over another (McClellan et al., 2006). An example might be a physiotherapist triaging all patients with limb injuries or a nurse treating all minor lacerations/abrasions. However, it should be noted that these strategies are not necessarily cost-effective. A UK randomised control trial (RCT) showed greater patient satisfaction in physiotherapist treatment of soft tissue injuries, but no resultant cost savings have been reported (Richardson et al., 2005). However, as McKenna et al. (2009) suggest, determining cost savings is a difficult process. Different studies often adopt different methods of estimating and valuing resources, meaning it is difficult to identify the cost savings associated with changes in roles. These considerations suggest that whilst changing a role may be beneficial to improving some aspects of hospital performance, it may not be the most cost-effective measure and consideration must be given to the local context.

A fourth, but more complex approach is to expand the role of unregulated workers which often takes the form of 'learning on the job'. This approach to learning enables staff members to gain new skills in their own distinct work environment, rather than undertaking formal study offered by an external provider. It enables staff to develop practical skills through informal learning which are directly applicable to their particular work context. Such training may be less expensive than external study. Nonetheless, as Berings et al. (2008) suggest, it is important that learning and training be carefully structured to take into account the skill, complexity and required knowledge of nursing tasks. Additionally, there is a view that this approach may result in task shifting or 'skill creep' with serious repercussions if boundaries are not placed around aspects of practice to ensure safety and quality (McKenna et al., 2004). For example Bridges et al. (2003), Bridges (2004) describe the interprofessional care co- 
ordinator role intended to be a clerical support role. There were four individuals in this role without any professional qualifications. Two years after its introduction, the scope of work had changed significantly without the organisation's knowledge. Occupants of this role were involved in discharge planning of inpatients with very complex needs, posing some threat to patient safety. The authors believed that this was due to the absence of training, close supervision of work and a regulatory system, concluding that cross-boundary work is difficult to regulate when undertaken by those without registrable qualifications.

Whenever changes to workforce roles are introduced, it is important to consider the particular context of the ward or unit or, in this case, the specific ED. There needs to be an acknowledgement that there are boundaries which impede staff achieving their potential, which may then impact on service delivery (Department of Health, 2000) and these boundaries may vary between what may appear to be similar EDs. Hyde et al. (2004, 2005) found that role re-design worked best when introduced locally involving local key stakeholders, where local willingness to hand over tasks existed and usually required local training programmes. However, these actions lack recognition and certification of transferable skills. The authors concluded that the spread and sustainability of new roles nationally is questionable as they may lack local relevance (Hyde et al., 2005). This would be true in most countries, Australia included.

\section{The ED workforce of the future}

Today's health care employees have increased expectations of autonomy, authority and responsibility (Finn, 2001). They want to be able to diagnose and treat minor injuries/complaints, undertake nurse-initiated X-rays, provide nurse-initiated analgesia and discharge patients in a timely and appropriate manner. This model has been successful in Western Australia (Combs et al., 2007), where nurses are providing a more advanced clinical service to patients resulting in an improvement in staff morale, and a less congested ED with the majority of patients fast-tracked. Also, in Melbourne, Australia, the introduction of new services into EDs (care coordination team, short stay unit, psychiatric team, chest pain unit, pharmacy service and others) as well as a 'fast track' system for low acuity patients, has proved successful in improving patient flow, although a cost-analysis has not been performed to date (McD Taylor et al., 2004). 
There is little doubt that there are core skills that the range of health professionals working in the ED will require; undertaking a rapid and comprehensive clinical assessment and history taking; assessment of deviations from 'normal'; the capacity to assess, treat, refer or discharge; timely and effective clinical decision-making; cross-disciplinary teamwork; managing the staff and environment; providing education and research and leadership (Brook and Crouch, 2004; Charters et al., 2005; Griffin and Melby, 2006). Nurses must consider their place in this environment and in particular, the potential for an expanded role. However, what is clear is that when determining the clinical roles of staff in an ED the decisions about roles must lie in the particular ED context and relate to the specific client needs and staff capabilities. There needs to be a local (ED) approach to roles and skill development but a national or, ideally, international, approach to nomenclature and regulation for clarity and public safety.

\section{Conclusions}

There is little doubt that demand for ED services will increase. Given projected nursing shortages of between 10,000 and 40,000 nurses by 2010 (AHWAC, 2004; Karmel and Li, 2002; Moore, 2007; Productivity Commission, 2005) as well as shortages of medical practitioners (Australian Medical Association, 2005), the Australian ED workforce is also likely to look different in years to come. Currently in Australia the targets used to measure ED effectiveness and efficiency do not include any measure of workforce capacity to meet these targets. Measuring ED workloads and ensuring that there is appropriate staffing to meet these workloads should be a priority.

There are real opportunities for expanding the nursing role and the roles of all health disciplines in EDs (Hudson and Marshall, 2008). However, this will require putting strategies in place to support the basic but essential clinical practice elements such as teamwork, handover and effective communication, which are not likely to change when work roles do. Organisations which have stable staffing levels will improve efficiency and effectiveness in all areas including the ED. As the roles and the teamwork become second nature to members of an ED, this will result in a well practiced and organised group of health professionals delivering coordinated and high quality health services to their patients. These groups will 
anticipate appropriate actions and work at intuitive levels. Finally, it should be noted that future health care services may be quite different from current models, and as a consequence, professional health care roles and an understanding of these roles will need to evolve in response to contemporary needs but in a staged and well considered manner. One final cautionary note - one size will not fit all!

\section{Conflict of interest statement}

None declared.

\section{Funding source}

None declared.

\section{References}

AHWAC, 2004. The Australian Nursing Workforce - An Overview of Workforce Planning 2001-2004. Australian Health Workforce Advisory Committee, Sydney, NSW.

Aiken, L.H., Clarke, S.P., Sloane, D.M., Sochalski, J.A., Busse, R., Clarke, H., Giovannetti, P., Hunt, J., Rafferty, A.M., Shamian, J., 2001. Nurses' reports on hospital care in five countries. Health Affairs 20, 43.

Australian Government Department of Health and Ageing, 2009. The State of Our Public hospitals: June 2009 Report, Canberra.

Australian Institute of Health and Welfare, 2008. Australian Hospital Statistics, 2006-2007. Health Services Series Number 31. Cat. No. HSE 55, AIHW, Canberra.

Australian Institute of Health and Welfare, 2009. Australian Hospital Statistics 2007-2008. Health Services Series No. 33. Cat. No. HSE 71, AIHW, Canberra. 
Australian Medical Association, 2005. Review of Health Workforce: Submission to the Productivity Commission. <http://www.ama. com.au/web.nsf/doc/WEEN-6EW44C> (accessed 11.03.09).

Australian Nursing and Midwifery Council, 2006. National Competency Standards for the Nurse Practitioner. <http://www.anmc.

org.au/docs/Publications/Competency\%20Standards\%20for\%20-

the\%20Nurse\%20Practitioner.pdf> (accessed 7.01.09).

Berings, M., Poell, R., Gelissen, J., 2008. On-the-job learning in the nursing profession: developing and validating a classification of learning activities and learning themes. Personnel Review 37, 442.

Bridges, J., 2004. Workforce Matters: Exploring a New Flexible Role in Health Care. City University, London.

Bridges, J., Meyer, J., Glynn, M., Bentley, J., Reeves, S., 2003. Interprofessional care coordinators: the benefits and tensions associated with a new role in UK acute health care. International Journal of Nursing Studies 40, 599.

Brook, S., Crouch, R., 2004. Doctors and nurses in emergency care: where are the boundaries now? Trauma 6, 211.

Brown, J., Gray, C.S., 1998. Stemming the tide of readmissions: patient, practice or practitioner? Reviews in Clinical Gerontology 8, 173.

Buchan, J., Ball, J., O’May, F., 2001. If changing skillmix is the answer, what is the question? Journal of Health Service Research Policy 6, 233. 
Charters, S., Knight, S., Currie, J., Davies-Gray, M., Ainsworth-Smith, M., Smith, S., Crouch, R., 2005. Learning from the past to inform the future - a survey of consultant nurses in emergency care. Accident \& Emergency Nursing 13, 186.

College of Emergency Nursing Australasia, 2007. Media Release.

<http://www.cena.org.au/pdfs/MR_2007-09-28.pdf> (accessed 19.12.08).

Combs, S., Chapman, R., Bushby, A., 2007. Evaluation of fast track. Accident \& Emergency Nursing 15, 40.

Committee on the Future of Emergency Care in the United States Health System, 2006. Hospital-Based Emergency Care: At the Breaking Point. The National Academies Press, Washington, DC.

Currie, J., Edwards, L., Colligan, M., Crouch, R., 2007. A time for international standards? Comparing the emergency nurse practitioner role in the UK, Australia and New Zealand. Accident \& Emergency Nursing 15, 210.

Daly, W.M., Carnwell, R., 2003. Nursing roles and levels of practice: a framework for differentiating between elementary, specialist and advancing nursing practice. Journal of Clinical Nursing 12, 158.

Demir, E., Chaussalet, T.J., Xie, H., Millard, P.H., 2008. Emergency readmission criterion: a technique for determining the emergency readmission time window. IEEE Transactions on Information Technology in Biomedicine 12, 644.

Department of Health, 2000. The NHS Plan. Department of Health, London. 
Duffield, C., Diers, D.K., Aisbett, C., Roche, M.A., 2009a. Churn: patient turnover and casemix. Nursing Economics 27, 185.

Duffield, C., Gardner, G., Chang, A., Catling-Paull, C., 2009b. Advanced practice nursing: a global perspective. Collegian 16, 55.

Duffield, C., Pelletier, D., Donoghue, J., 1994. Role overlap between clinical nurse specialists and nursing unit managers. Journal of Nursing Administration 24, 54.

Elliot, A., 2002. Decline in Bulk Billing: Explanations and Implications (Current Issues Brief 2002-2003). Commonwealth Government, Canberra.

Elsom, S., Happell, B., Manias, E., 2009. Nurse practitioners and medical practice: opposing forces or complementary contributions? Perspectives in Psychiatric Care 45, 9.

Finn, C.P., 2001. Autonomy: an important component for nurses' job satisfaction. International Journal of Nursing Studies 38, 349.

FitzPatrick, M.K., Reilly, P.M., Laborde, A., Braslow, B., Pryor, J.P., Blount, A., Gaskell, S., Boris, R., McMaster, J., Ellis, J., Fontenot, A., Telford, G., Schwab, C.W., 2006. Maintaining patient throughput on an evolving trauma/emergency surgery service. Journal of TraumaInjury Infection \& Critical Care 60, 481.

Gardner, W., Kelleher, K.J., Wasserman, R., Childs, G., Nutting, P., Lillienfeld, H., Pajer, K., 2000. Primary care treatment of pediatric psychosocial problems: a study from pediatric research in office settings and ambulatory sentinel practice network. Pediatrics 106, e44.

Garling, P., 2008. Final Report of the Special Commission of Inquiry. Acute Care Services in NSW Public Hospitals, State of NSW, Sydney. 
Griffin, M., Melby, V., 2006. Developing an advanced nurse practitioner service in emergency care: attitudes of nurses and doctors. Journal of Advanced Nursing 56, 292.

Guzik, A., Menzel, N.N., Fitzpatrick, J., McNulty, R., Guzik, A., Menzel, N.N., Fitzpatrick, J., McNulty, R., 2009. Patient satisfaction with nurse practitioner and physician services in the occupational health setting. AAOHN Journal 57, 191.

Harrison, M.I., Henriksen, K., Hughes, R.G., 2007. Improving the health care work environment: implications for research, practice, and policy. Joint Commission Journal on Quality \& Patient Safety 33, 81.

Hooker, R.S., 2004. Physician assistants in occupational medicine: how do they compare to occupational physicians? Occupational Medicine (Lond) 54, 153.

Hooker, R.S., 2006. Physician assistants and nurse practitioners: the United States experience (see comment). Medical Journal of Australia 185, 4.

Hudson, P.V., Marshall, A.P., 2008. Extending the nursing role in emergency departments: challenges for Australia. Australasian Emergency Nursing Journal 11, 39.

Hyde, P., McBride, A., Walshe, K., Young, R., 2004. A Catalyst for Change? The National Evaluation of the Changing Workforce Programme, Manchester.

Hyde, P., McBride, A., Young, R., Walshe, K., 2005. Role Redesign: New Ways of Working in the NHS. <http://www.education.monash.edu.au/centres/ceet/docs/seminars /roleredesignpaper.pdf> (accessed 19.12.08). 
Jarman, H., 2007. The emergency care nurse role: a clinical staff attitude survey. Emergency Nurse 14, 26.

Jennings, N., Lee, G., Chao, K., Keating, S., Jennings, N., Lee, G., Chao, K., Keating, S., 2009. A survey of patient satisfaction in a metropolitan emergency department: comparing nurse practitioners and emergency physicians. International Journal of Nursing Practice 15, 213.

Jennings, N., O’Reilly, G., Lee, G., Cameron, P., Free, B., Bailey, M., 2008. Evaluating outcomes of the emergency nurse practitioner role in a major urban emergency department, Melbourne, Australia. Journal of Clinical Nursing 17, 1044.

Karmel, T., Li, J., 2002. The Nursing Workforce - 2010. National Review of Nursing Education, Canberra, ACT.

Lauder, S., 2007. Nurses Defend Handling of Miscarriage Cases. ABC Local Radio, Australia.

Maloney, C.G., Wolfe, D., Gesteland, P.H., Hales, J.W., Nkoy, F.L., 2007. A Tool for Improving Patient Discharge Process and Hospital Communication Practices: The "Patient Tracker'”.

Mark, D., 2009. Report Highlights Hospital Bed Shortage. A.M.-ABC News, Australia.

McClellan, C.M., Greenwood, R., Benger, J.R., 2006. Effect of an extended scope physiotherapy service on patient satisfaction and the outcome of soft tissue injuries in an adult emergency department. Emergency Medicine Journal 23, 384. 
McD Taylor, D., Bennett, D.M., Cameron, P.A., 2004. A paradigm shift in the nature of care provision in emergency departments. Emergency Medicine Journal 21, 681.

McKenna, H., Keeney, S., Hasson, F., 2009. Health care managers' perspectives on new nursing and midwifery roles: perceived impact on patient care and cost effectiveness. Journal of Nursing Management 17, 627.

McKenna, H.P., Hasson, F., Keeney, S., 2004. Patient safety and quality of care: the role of the health care assistant. Journal of Nursing Management 12, 452.

Metherell, M., 2003. GP Fees Soar When Bulk-Billing Scrapped, Sydney.

Moore, T., 2007. Rudd Addresses Nursing Shortage. <http://www. brisbanetimes.com.au/news/national/rudd-addresses-nursingshortage/ 2007/10/17/1192300830049.html> (accessed 02.07.09).

New South Wales Health, 2007. Key Drivers of Demand in the Emergency Department: A Hypothesis Driven Approach to Analyse Demand and Supply. NSW Health, Sydney.

NSW Department of Health, 2005. Nurse Practitioners and Midwife Practitioners in NSW.

NSW Health, 2005. Clinical Nurse Specialist Classification - Public Hospital Nurses' (State) Award Doc No. PD2005_432.

Pearson, A., 2003. Multidisciplinary nursing: re-thinking role boundaries. Journal of Clinical Nursing 12, 625. 
Productivity Commission, 2005. Australia's Health Workforce: Research Report.

Productivity Commission, Canberra, ACT.

Richardson, B., Shepstone, L., Poland, F., Mugford, M., Finlayson, B., Clemence, N., 2005. Randomised controlled trial and cost consequences study comparing initial physiotherapy assessment and management with routine practice for selected patients in an accident and emergency department of an acute hospital. Emergency Medicine Journal 22, 87.

Robert Wood Johnson Foundation, 2009. Addressing the Quality and Safety Gap - Part I: Case Studies in Transforming Hospital Nursing and Building Cultures of Safety.

Root, N., 2008. Advanced practice nurse role in community partnership for education. Journal of Emergency Nursing 34, 482.

Roschkov, S., Urquhart, G., Rebeyka, D., Scherr, K., 2004. Clinical nurse specialist or nurse practitioner? Canadian Nurse 100, 18.

Rutherford, J., Leigh, J., Monk, J., Murray, C., 2005. Creating an organizational infrastructure to develop and support new nursing roles - a framework for debate. Journal of Nursing Management 13, 97.

Sackett, D.L., 2009. A landmark randomized health care trial: the Burlington trial of the nurse practitioner. Journal of Clinical Epidemiology 62, 567.

Sammut, J., 2009. Why Public Hospitals are Overcrowded: Ten Points for Policy Makers. Centre for Independent Studies, Sydney. 
Shendell-Falik, N., Feinson, M., Mohr, B.J., 2007. Enhancing patient safety: improving the patient handoff process through appreciative inquiry. Journal of Nursing Administration 37, 95.

Vincent, C.A., Wears, R.L., 2002. Communication in the emergency department: separating the signal from the noise (comment). Medical Journal of Australia 176, 409.

Wallace, N., 2007. Casualty Crisis: Many Wait Eight Hours. Fairfax, Sydney.

Wilper, A.P., Woolhandler, S., Lasser, K.E., McCormick, D., Cutrona, S.L., Bor, D.H., Himmelstein, D.U., 2008. Waits to see an emergency department physician: US trends and predictors, 1997-2004. Health Affairs 27, w84.

Wilson, A., Shifaza, F., 2008. An evaluation of the effectiveness and acceptability of nurse practitioners in an adult emergency department. International Journal of Nursing Practice 14, 149. 